\section{Dental care risk management provided by Social Protection Institutions of Senegal}

\author{
Cheikh Mouhamadou Mbacké Lo, ${ }^{1}$ \\ Mbathio Diop, ${ }^{1}$ Aida Kanouté, \\ Massamba Diouf, ${ }^{1}$ Daouda Cissé, ${ }^{1}$ \\ Daouda Faye, ${ }^{1}$ Yandé Baldé ${ }^{2}$ \\ 'Department of Public Health, Faculty of \\ Medicine, Cheikh Anta Diop University, \\ Dakar; ${ }^{2}$ Dentist Public Practice, Dakar, \\ Senegal
}

\begin{abstract}
Nowadays in Senegal, located in West Africa, social protection institutions are confronted with a substantially increased healthcare expenditure in general, and oral care in particular. The ability of the leadership to use techniques to contain the impact of risks they are facing determine their viability. The aim of our study was to analyze the risk management of dental care coverage by those institutions. The study was descriptive, extensive and focused on all active social protection Institutions in Senegal since 2005, at least. Our results showed that, in spite of the implementation of risk management mechanisms such as patient co-payment (97\% of institutions), coverage ceiling (26\%) and dentist council (15\%), healthcare expenditure still growing. For the containment of oral care expenditure increase, it is important to raise awareness among social protection institutions for a greater use of existing risk management mechanisms.
\end{abstract}

\section{Introduction}

After independence days, health care coverage has evolved a great deal in African countries. In the 1970s in Senegal country located in West Africa, however, the State's disengagement from social sectors, in particular, healthcare, due to the economic downturn has dealt a blow to the free health care coverage inherited from the settlers' system. Facing a soaring of prices in the provision of care and drug prescriptions along with the population's financial restrictions to ensure direct and immediate payment of health care, authorities have developed strategies implementing a number of social protection institutions such as The Disease Prevention Institute (DPI) of business or interprofessional and mutual for care coverage. ${ }^{1-3}$ The implemented policies have hugely improved the health care system though with- out eradicating the problem due to a still growing cost of most provided care services such as oral care; a burden to those institutions' budget. ${ }^{4,5}$ It is then imperative for them to contain the moral risk through a well-managed oral care coverage. Moral risk indicates an insured person's behavior to use health care services more reasonably than if non-assured, due to the elimination or reduction of financial barrier towards health services. ${ }^{6,7}$

\section{Materials and Methods}

The study was conducted in Dakar, where $90 \%$ of social protection institutions are located. It was a descriptive and extensive analysis and has covered all social protection institutions. Requirements to be included in the analysis were to be active since at least 2005 , date of the first established national health accounts in Senegal.

Data about the institutions was gathered via correspondences to the leadership of the Senegalese Disease Prevention Institute Federation and the United Health mutual. Upon receipt, self-administered questionnaires were sent to the managers for a lock-up period of 1 month.

The study targeted the offered services, the method of coverage with co-payments (i.e. part of the responsibility of the recipient), the availability or not of a coverage ceiling or of a dentist council to prevent any potential abuse of care services from both providers and patients. CSPRO (US Census bureau, Washington, DC) and SPSS (IBM Corp. New York, USA) software were used to process the data collected.

\section{Results}

Of the 220 self-administered questionnaires, 127 were received with only 40 with usable data on $25 \mathrm{DPI}$, specified as 13 businesses, 12 interprofessional, and 15 health mutual.

\section{Discussion}

\section{Study boundaries}

The amount of information received, despite the forged relationship with SPS's managers, denotes the non-reliability of autoadministrated questionnaires. Thus, we think a meeting-based survey would maximize the collect of information. However, because answers to some questions require access to
Correspondence: Cheikh Mouhamadou Mbacké Lo, Department of Public Health, Faculty of Medicine, University Cheikh Anta Diop of Dakar, Stade Iba Mar Diop BP 3256, Senegal.

E-mail: cheikhlo54@yahoo.fr

Key words: social protection institutions; risks management; dental Care; Senegal.

Contributions: the author contributed equally.

Conflict of interest: the authors declare no potential conflict of interest.

Received for publication: 13 June 2016.

Accepted for publication: 16 June 2016.

This work is licensed under a Creative Commons Attribution NonCommercial 3.0 License (CC BYNC 3.0).

(C) Copyright C.M.M. Lo et al., 2015

Licensee PAGEPress, Italy

Journal of Public Health in Africa 2015; 6:564

doi:10.4081/jphia.2015.564

the archives, it was not a proper method. Nevertheless, the survey would provide with better results if the targeted institutions' managers were made aware of their potential impact on the improvement of people's oral care. We think that the results from the surveyed institutions (business, interprofessional and community-based) show the barriers confronted by the involved businesses, interprofessional and community-based institutions.

\section{Services offered}

All institutions but the community-based ones $(6.6 \%)$ provide with conservative and extractions coverage (Table 1).

For the prosthetic care it is covered with a relatively low percentage of $27.6 \%$ by businesses based institutions and $33.7 \%$ by the interprofessional. Such coverage is non-existent $(0 \%)$ with community-based institutions despite the fact that Lo's survey in Dakar indicates 4 out of 28 of mutual (14.3\%) provide with prosthesis coverage. The method used to conduct the survey might explain that fact (Table 1). ${ }^{1}$

The orthodontic coverage is very high among interprofessional-based institutions (72.3\%), relatively low in those of businesses (27.6\%) and nonexistent in community-based institutions (Table 1). Such disproportion might be due to the fact that dentures coverage is more about aesthetic, which requires big resources, than functionality

Both prosthetic and orthodontic care are less important among institutions (22 and $42.4 \%$ ) compare to another type of care. In fact, larger is an insurance structure, more 
shared is the risk and less costly it becomes for everyone. The inequalities in dental care coverage along with the renouncement of the less-favored to health care due to financial restrictions are blocking factors to prosthetic and orthodontic coverage by institutions.

\section{Risk management}

The ability of the insurance system's leadership to use techniques to contain the impact of risks they are facing, determines their viability. Mainly co-payment and coverage ceiling were the methods of controlling used by institutions for risk containment.

The implemented co-payment seems to be an adequate method of control and does not incur additional costs for the institution. Thus, $97 \%$ of surveyed institutions have used it including $100 \%$ of community-based and interprofessional institutions (Figure 1). According to a review by BIT (2007), ${ }^{2}$ the patient co-payment is a double standard as it is an efficient means to contain moral risk but might contribute, when high, to limit the accessibility of treatment as well; contrary to social protection policy.

The medical coverage ceiling appears to be efficient in containing potential frauds and abuses and does not incur additional costs. Thus, it is mainly used by mutual due to their financial restrictions (49\%) (Figure 2) and according to a survey conducted by Lo and colleagues (2011), ${ }^{1} 75 \%$ have used it.

The dentist council enables the control of compliance with therapeutic schemes to prevent any abuse in care services by both providers and consumers. However, such method entails additional cost to the institutions, which makes it not accessible by community-based institutions due to their financial restrictions. Having said that, as a point of order, a protocol of treatment by compelling services provider to prescribe functional treatment and generic drugs were adopted. Nevertheless, the strategy became a burden among mutual when some of them were refused a reimbursement of their due. ${ }^{1,8}$

The results show that most institutions (85\%) lack means to evaluate the quality of care provided and application management of current pricing (Figure 3). That's why we think it is necessary to regulate the system of the convention of care providers. Such system should incite them to accept to conform to the norms of quality, the protocols of evaluation, and to the current pricing defined by the Ministry of Health in collaboration with providers.

It should be noted that even if these mechanisms reduce the moral risk, they could be a discouraging factor to insured patients who postpone their treatments. Such action can contribute to a high care cost due to the aggravation of disease. . $^{8-10}$

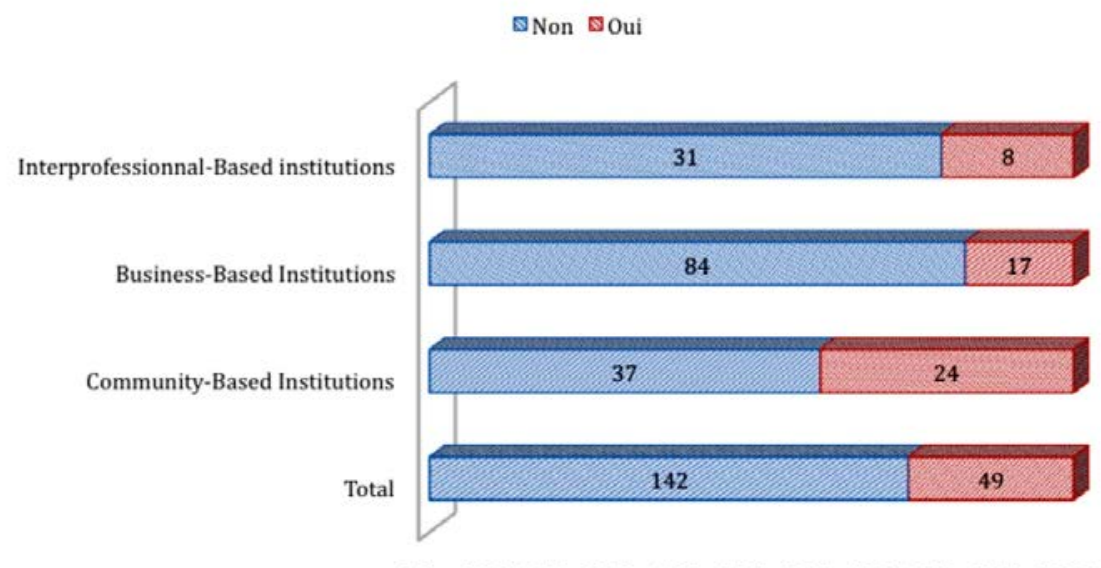

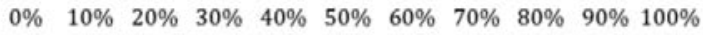

Figure 1. Proportion of institution using co-payment.

Interprofessionnal-Based institutions

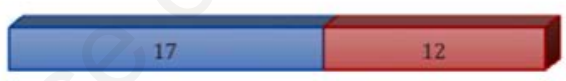

Business-Based Institutions

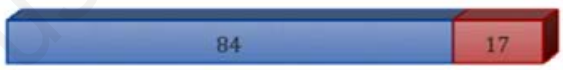

Community-Based Institutions

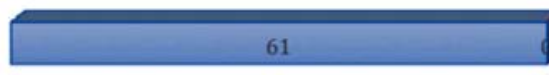

Total

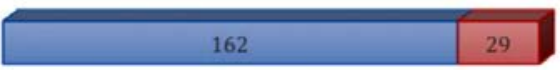

$0 \% 10 \% 20 \% 30 \% 40 \% 50 \% 60 \% 70 \% 80 \% 90 \% 100 \%$

Figure 2. Proportion of institution using medical coverage ceiling.

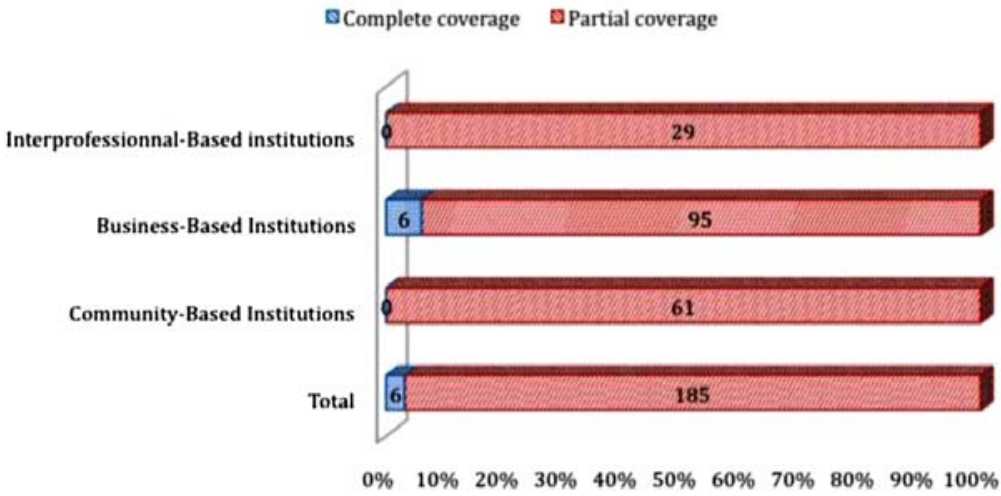

Figure 3. Proportion of institutions lacking means to evaluate the quality of care provided and application management of current pricing. 
Table 1. Proportion of institutions according to the type of dental care.

\begin{tabular}{|c|c|c|c|c|}
\hline Type of dental treatment & $\begin{array}{c}\text { Interprofessional-based } \\
\text { institutions, } \%\end{array}$ & $\begin{array}{c}\text { Institutions } \\
\text { Business-based } \\
\text { institutions, \% }\end{array}$ & $\begin{array}{l}\text { Community based } \\
\text { institutions, } \%\end{array}$ & Total, $\%$ \\
\hline Conservative treatment & 100 & 100 & 93.4 & 97.9 \\
\hline Extractions & 100 & 100 & 100 & 100 \\
\hline Prothesis & 27.6 & 33.6 & 0.0 & 22.0 \\
\hline Orthodontics & 27.6 & 72.3 & 0.0 & 42.4 \\
\hline
\end{tabular}

\section{Conclusions}

Implemented methods such as the co-payment, coverage ceiling and the dentist council by social protection institutions in Senegal might allow containing the hike of dental care expenditure. Thus, besides those strategies, communication and information of health professionals, and patients about their rights and duties is essential. However, we must make efforts to end abuses and deviance noticed on both sides.

\section{References}

1. Lo CMM, Cisse D, Diouf M, et al. Prise en charge de la prothèse dentaire par les mutuelles de santé de la région de Dakar.
Rev Col Odonto-Stomatol Afr Chir Maxillofac 2011;18:23-6.

2. Bureau International du Travail (BIT). La protection sociale de la santé: stratégie de l'OIT pour un accès universel aux soins de santé. Rev BIT; 2007. p 102.

3. Gotzhuber, Jurgen H, Kirsten R. Mutuelle de santé, 5 années d'expérience en Afrique de l'Ouest débats, controverses et solutions proposées par GTZ. Rev Santé Protec Soc 2003. p 72.

4. Gobbers D L'Equité dans l'accès aux soins en Afrique de l'Ouest Débats contre verses et solutions proposées. Rev ADSP 2002;38:77.

5. Letourmy A. Le développement de l'assurance maladie dans les pays à faible revenu: l'exemple des pays africains. Rev Acad Sci 2008;331:952-63.

6. Lo CMM, Cisse D, Faye D, et al. Accessibilité financière des soins bucco dentaires aux populations du département de Thiès. Rev Col Odonto-Stomatol Afr Chir Maxillo-Fac 2009;16:41-5.

7. Nathalie M. Contributions actuelle et potentielle des mutuelles de santé au financement et à la fourniture et à l'accès aux soins de santé cas du Sénégal.Rev. BIT- STEP: Africa; 1998. p 20.

8. Lo CMM, Faye D, Cisse D, et al. Prise en charge des soins bucco-dentaires par les mutuelles dans le département de Thiès Rev Col Odonto-Stomatol Afr Chir MaxilloFac 2008;15:28-32.

9. Wagstaff A. Pauvretés et inégalités dans le secteur de la santé. Bull Org Mond Santé 2002;7:101-8.

10. Aviva R. Faire des soins de santé une prestation de sécurité sociale: approches institutionnelles de l'extension de la couverture. Rev Int Séc Soc 2010;63. 